\title{
Investigation into the Impacts of Artisanal Gold Mining on the Livelihood Foundation of Baomahun Community in Southern Sierra Leone
}

\author{
Ishmail Sheriff', Alhaji Brima Gogra ${ }^{2 *}$, Bashiru M. Koroma ${ }^{2 *}$ \\ ${ }^{1}$ Institute of Environmental Management and Quality Control, School of Environmental Sciences, Njala University, Freetown, \\ Sierra Leone \\ ${ }^{2}$ Chemistry Department, School of Environmental Sciences, Njala University, Freetown, Sierra Leone \\ Email: ^agogra@njala.edu.sl, ‘bashiru.koroma@yahoo.com
}

How to cite this paper: Sheriff, I., Gogra, A.B. and Koroma, B.M. (2018) Investigation into the Impacts of Artisanal Gold Mining on the Livelihood Foundation of Baomahun Community in Southern Sierra Leone. Natural Resources, 9, 42-54. https://doi.org/10.4236/nr.2018.92004

Received: December 22, 2017

Accepted: February 23, 2018

Published: February 26, 2018

Copyright $\odot 2018$ by authors and Scientific Research Publishing Inc. This work is licensed under the Creative Commons Attribution International License (CC BY 4.0).

http://creativecommons.org/licenses/by/4.0/

(c) (i) Open Access

\begin{abstract}
Artisanal gold mining has a long history in Sierra Leone. Mining is the most important economic activity in the communities endowed with minerals. Many people who are often disadvantaged in the labour market are engaged in this sector. The poor implementation of mining laws and regulations is fueling the rate of involvement in the sector. In-depth studies of the effect of artisanal mining activities on the livelihood strategy of non-miming population in Sierra Leone are rare. The overarching objective of this work is to bring to light the effect of artisanal gold mining on the environment and livelihood of local resident with a case study of Baomahun, Delenga Section of Valunia Chiefdom, Bo District, Southern Sierra Leone. The study population comprised of people residing at the study area as at 2015. The primary sampling units included elements from the Baomahun vicinity such as miners, mines monitors, conservation agents and local residents of the village. The sample frame employed in this study was the random selection of artisanal miners at each site where mining was being undertaken, mines monitoring officers, conservation agents and local residents. Sample size was 76 people. This was done to indicate proper representation of the study area. And also 76 questionnaires were administered to miners, mines monitors, conservation agents and local residents. Both primary data and secondary data were used in the study. Detailed explanation of the analyses was accomplished by both qualitative and quantitative methods. The study revealed that there are varied degrees of visible impacts of artisanal mining on the environments. They include soil depression; creation of water pools in abandoned unfilled mines and di-
\end{abstract}


version, and turbidity of local streams. Artisanal mining as an economic activity has imparted both positively and negatively on the livelihood of resident. Significant gaps and disparities exist in the implementation of the current Mines and Minerals Act of 2009 on the artisanal mining sector.

\section{Keywords}

Artisanal Mining, Livelihood Foundation, Baomahun, Questionnaire, Environment

\section{Introduction}

Economic development in Sierra Leone is underpinned by the endowment of the natural resource base. The country is clothed with impressive mineral resources and the mining sector remains the most important component of the economy outside of agriculture in terms of economic value and foreign exchange earnings [1]. The phenomenal increases in world consumption for precious metals of gold have encouraged a boom in investment the sector worldwide [2]. Thus, many informal people or non-agricultural workers in rural communities and regions who lack diversified livelihood strategies have entered the sector [3]. They see mining as a safety net that produces higher output than other locally feasible livelihood strategies [4].

Because the sector is characterised with inadequate legal and regulatory framework and also faced with problems such as isolation from the mainstream of economic development, environmental and social effects, are often being ignored [5].

There is significant body of existing credible scientific literature on mining in general as a concept, in Sierra Leone. The data that exist for reliable analysis of the real social and environmental impact of the sector in the study area are laden with inaccuracies, fissures, and inconsistencies. The study sought to give a detail presentation on the imbalance between artisanal gold mining as an economic activity and its associated overlook implication on the environmental and livelihood foundation of local residents.

This study will therefore help provide novel information on the gaps and disparities that exist in the implementation of mining policies that will help strengthen the environmental monitoring unit of the Environmental Protection Agency-Sierra Leone (EPA-SL) as well as that of the Sierra Leone's National Mineral Agency (NMA). It will inspire decision makers at all levels charged with the responsibility of developing and implementing policies to balance social and economic concerns with environmental ones.

Questions on this complex issue are manifold in the development context. However; the researcher is therefore, interested in answering:

1) Have artisanal gold mining methods and processes led to environmental externalities in the area?

2) Have artisanal mining operations affected the livelihood foundation of in- 
digenous people in the study area?

3) What is the extent to which mining laws have been enforced and policies implemented to ensure compliance to social, environmental, standards?

The objective of this study were to investigate the impact of artisanal gold mining on the environment and livelihood of local community by: 1) identifying and assessing the methods and processes of artisanal gold mining, 2) determining the impact of these methods and processes on the environment, 3) assessing the impacts of artisanal mining on the livelihood foundation of local residents, 4) assessing the effectiveness of existing national mining act in the Baomahun community with the principal aim of identifying significant gaps and disparities that may exist in the implementation..

\section{Material and Methods}

\subsection{Description of Study Area}

Baomahun is located in the Delenga Section of the Valunia Chiefdom, Bo District in the Southern Province of Sierra Leone. It is about $60 \mathrm{~km}$ (37 miles) away from the provincial head quarter town of Bo. It shares boundaries with Gbonkolenken Chiefdom to the North and Kamajei Chiefdom in the South.

Baomahun, in common with the rest of Sierra Leone, experiences a wet semi equatorial climate characterized by an alternation of the wet and dry season. The wet season is between mid-May and mid-November. The average rainfall is 2860 mm. In Baomahun the dry season falls between late-November and April. The average annual temperature is $26.2^{\circ} \mathrm{C}$.

Baomahun is an area of exceptional biological importance, hosting the Kangari Hills forest reserves which abound in richness of species and endemism.

Population and Housing Census Statistics conducted in 2004 indicates estimated population of 3543 but this number would have reduced considerably because mining was not at its highest peak due to the Ebola outbreak.

The major economic activities around the landscape in Baomahun are: rotational subsistence agriculture, mining, logging, fishing (mostly practiced in the dry season), commercial motorcycle riding and trade.

\subsection{Research Design}

This work was designed with the aim to collect information on the impact of artisanal gold mining on the environment and the livelihood foundation of local communities.

\subsubsection{Study Population}

The study population comprised of people residing at the study area as at 2015 . The primary sampling units included miners, mines monitors, conservation agent and local resident of the study area.

\subsubsection{Sample Frame}

The sample frame employed in this study was stratified random selection of ar- 
tisanal miners at each site where mining was being undertaken, mines monitoring officers, conservation agents and local residents.

\subsubsection{Sample Size}

Sample size was 76 people: miners 30 (39.48\%), local residents $40(52.63 \%)$ and key stakeholders 6 (7.89\%). This was done to indicate proper representation of the study area.

\subsection{Sources of Data}

The data for this study was obtained from both primary and secondary sources.

\subsubsection{Primary Data}

Primary data was obtained using a combination of methods, including participant observation, field visits to old and current site, and personal respondent interviews to allow for verification of information memories and to be alert for potential sources of bias in other data. A semi-structural questionnaire was administered to the target groups that form the sample size.

\subsubsection{Secondary Data}

Secondary data was obtained by consulting relevant agency publications and routine data collected by state agencies, publication in books, articles from journals, periodicals, encyclopedias, files of local news-papers and; project report of researches conducted related to the research topic.

\subsection{Research Instruments}

The study required the use of the following instruments in order to arrive at the appropriate findings.

1) Documentary analysis or desktop reviews of existing previously reviewed and screened literature that is pertinent to the research topic.

2) Administering of questionnaire was the main survey instrument.

3) iPhone mini-5 for recording schedule.

4) Digital camera for photographic documentation of mine sites and other features relevant to the study.

\subsection{Data Collection Procedure/Research Technique}

Field visitation was carried out at regular intervals in the period of October-December 2015 to engage stakeholders on the rationale of the research. After identifying a site or a household in the case of local residents, the researcher explained the purpose of the study and terms of privacy were assured in order to gain confidence of the respondent. The researcher had letter of introduction which he showed the respondents for authentication. The research technique employed includes Structured and Semi-structured interview in order to examine their perceptions on how mining activities impact the environments and the livelihood foundation of local population. 


\section{Data Analysis}

Double data entry was employed to help check errors in data capture, and the database development involved customization of the Microsoft Excel spreadsheet to input information in both string and numeric formats in order to developed frequency distribution tables' charts, graphs among others.

\section{Results and Discussions}

\subsection{Methods of Artisanal Gold Mining in Baomahun}

The method(s) of gold mining depend on the ecology, size of ore deposit of the gold mine. The study revealed that the open pit mining method recorded the widely used artisanal gold mining method in the study area, as confirmed in the questionnaire administered $100 \%$ while underground mining method recorded the least $16.67 \%$ used by miners in their operations (Figure 1).

\subsubsection{The Open Pit Surface Mining Method}

This method is applied in swamps within the enclave of Cluff Gold concession area and in Kangari forest reserve areas. This method recovers valuable minerals from large, thick ore bodies lying close to the surface of the earth miners prepare the ground at a pre-prospected site, and excavate the pay material or earth overburdens. The depth of the pit depends on the depth of the gold bearing gravel. Then they pile it up for washing to separate and recover the valuable products. Mining pits are constantly being filled with water as miners dig. Small Petrol driving pumps preferably E-Y 20 Robin are used for dewatering the pit but sometimes bailing out of the pit was done by hand using head pans. The open pit surface mining usually disturbs much large area. These miners leave behind pit ranging in dimension from $2 \mathrm{~m} \times 2 \mathrm{~m}$ to $200 \mathrm{~m} \times 600 \mathrm{~m}$ (Plate 1 ).

\subsubsection{The Underground Mining Method}

This is employed by artisanal gold miners when the rock-bearing ore lies deep beneath the surface of the earth to get out with surface mining. First the miners

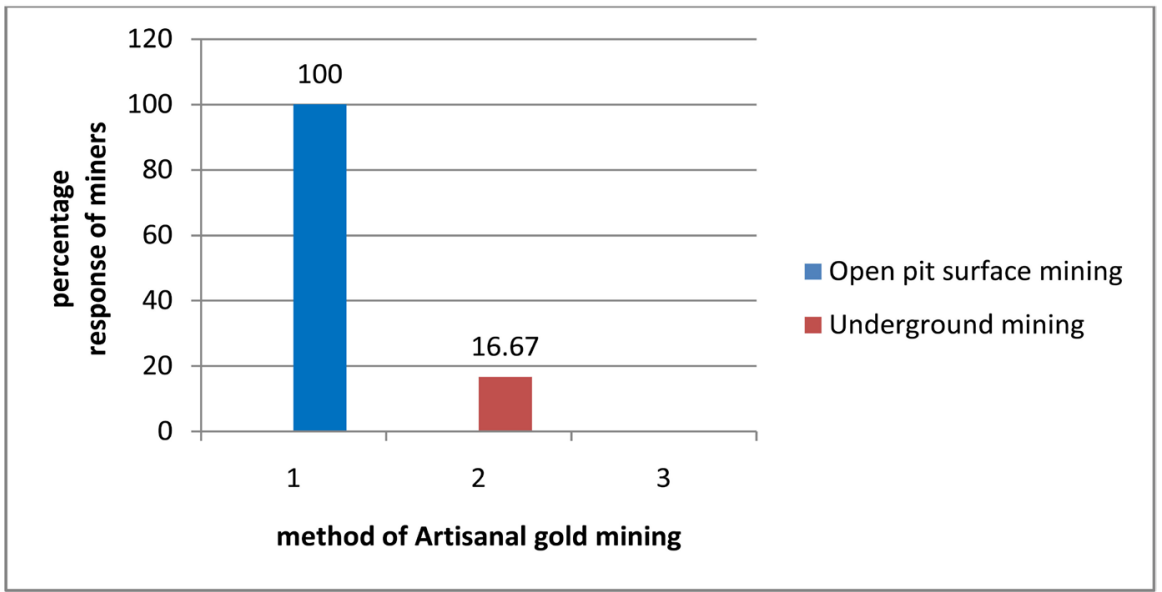

Figure 1. Artisanal miners' response on methods of gold mining in Baomahun (Source: Author's field survey data, 2015). 


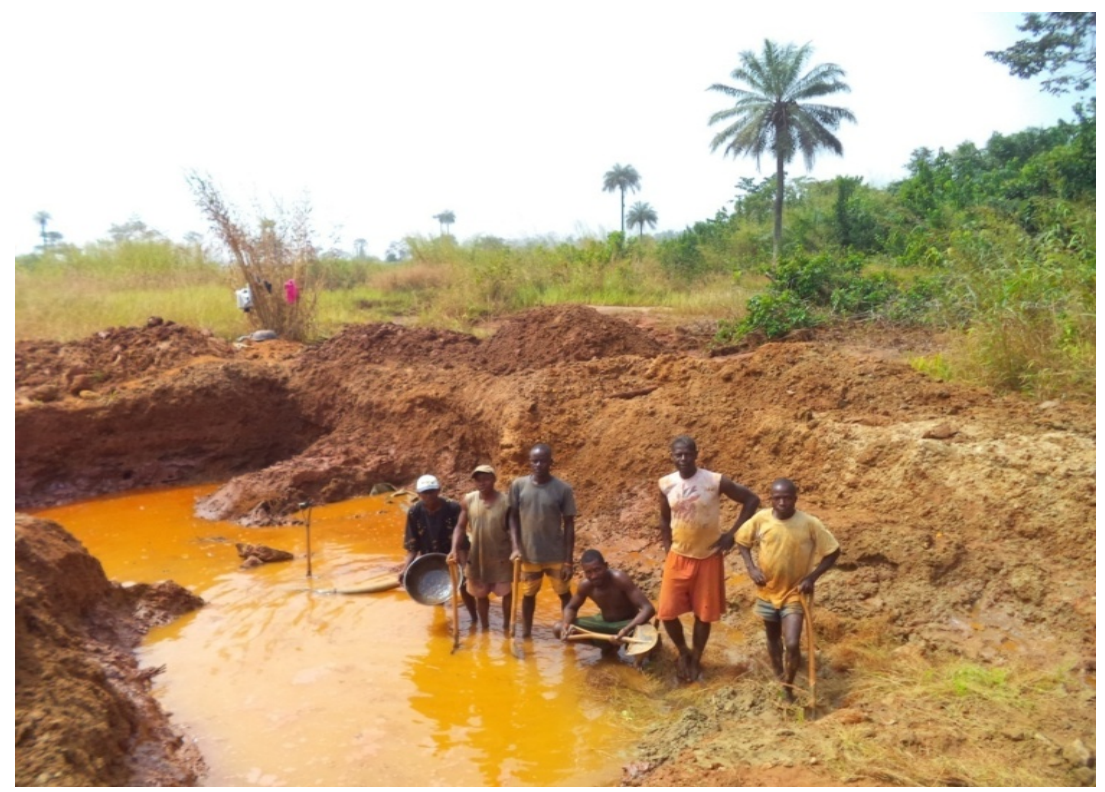

Plate 1. Artisanal miners working in an open pit filled with water. (Source: Author's field survey data, 2015).

dig a vertical opening into the mine called a shaft using hand tools such as hammers; hand forged scrap-steel chisels and spades. Then they drive a nearly horizontal or sloping mine entrance passage into the side of the hill called an adit. From these main passages, miners dig systems of horizontal passages called levels running the risk of collapsed walls and oxygen shortages to extract the gold that the world demands. However, some miners used old adit left by former mining company in the area.

\subsection{Processes (Techniques and Procedures) of Artisanal Gold Mining in Baomahun}

\subsubsection{Sluicing}

A simple wooden rectangular sluice box a few feet in length called canoe is used for washing the gravel. A dark red wool carpet is put inside the canoe to trap gold particles, and wire mesh is placed inside the box to retain large stones and other unwanted materials. A series of wooden rifles or steps are placed on its route designed to help break the flow velocity of the water as it travel down the sluice. The mineral-bearing gravel and sand are first shovelled into the upper end of the canoe and are washed by the force of water shooting out through a small petrol driving pump mostly E-Y 20 Robin. The force generated keeps gold particles from sinking easily. As moving water carry the ore or alluvium down the steps of wooden riffles that had been earlier placed on its route, the carpet and riffles covering the bottom of the sluice trap the gold particles. When the gravel removed for washing is finished, the water source (small petrol-driven pump) is turned off and the carpet contents are ready to be removed. Carpets or other capturing devices on the bottom of sluices can be removed and washed in a big rubber bowl to remove the captured dense material (Plate 2). 


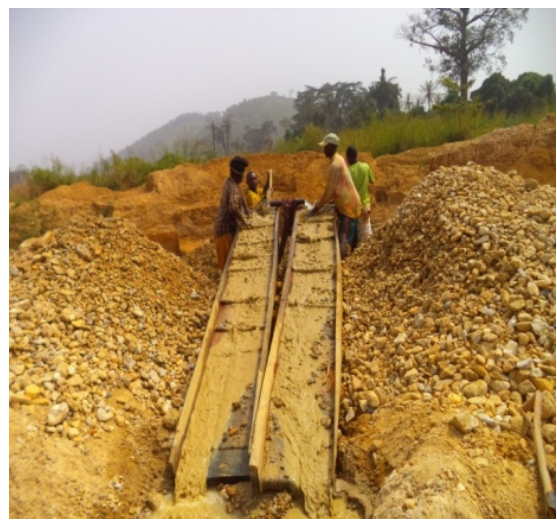

(a)

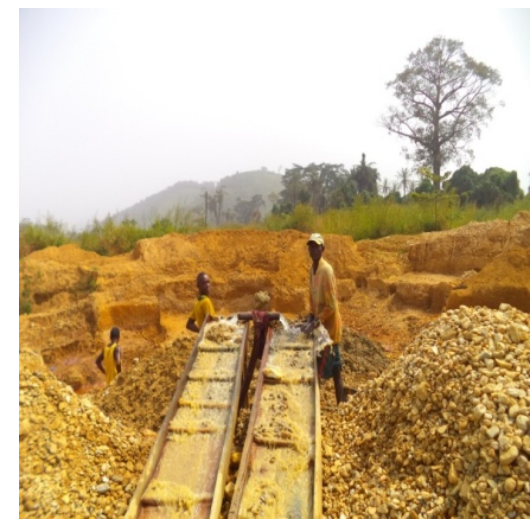

(b)

Plate 2. Artisanal gold washing process in Baomahun using a wooden sluice box. (Source: Author's field survey data, 2015).

\subsubsection{Panning}

Panning is often done after sluicing have been completed. The carpets content of pebbles and sand that stick to the gold in the sluice box is washed in a big rubber bowl to remove the content and the dense materials are placed in a medium sized, curved head pan along with water to separate heavy gold particles from other lighter particles. This last stage of requires the service of experienced and professional gold miners. After a succession of shifts designed to get rid of lighter sediments along with water have been completed, gold due to it density, will be exposed on the bottom of the head pan for the miner to recover. The decision to either uses elemental mercury or not is made at this stage but it all depends on the size of the gold. The final content is heated with fire in a head pan to dry up water left and recover the gold.

\subsection{Use of Mercury as Supplementary Recovery Techniques}

Mercury is used for gold amalgamation in artisanal mining as an affordable means to pick up small gold particles from sediment. In this process mercury and gold-carrying silt are combined to create a hardened amalgam, the amalgam is later heated over an open flame to separate the mercury from the gold.

Majority 24 (80\%) of the miners denied ever using mercury while a few $6(20 \%)$ miners admitted to the use of chemical, particularly mercury (Plate 3 ).

\subsection{Effect(s) of Artisanal Gold Mining on the Environment}

Mineral extraction is the most destructive industry to the environment and artisanal mining is a major contributor to this destruction [6]. There were varied degrees of visible impacts of artisanal mining on the environments in Baomahun.

Results from the analyzed data collected show visible effects like soil depression to be the highest percentage recorded $37.11 \%$. This is associated with haphazard excavations [2]; and [7]. The creation of water pools in abandon unfilled mines that become traps for animals and breeding grounds for vector of 


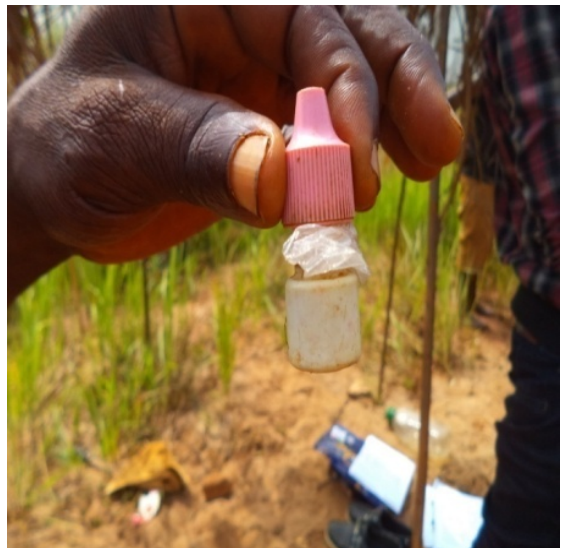

(a)

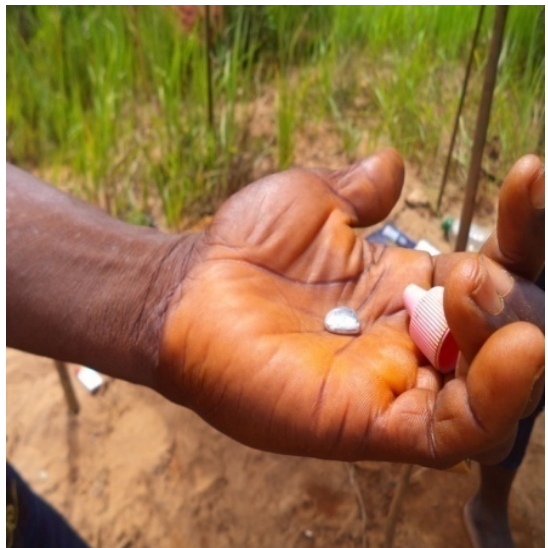

(b)

Plate 3. An artisanal gold miner holds mercury container and mercury amalgam in his palm within Cluff gold concession area in Baomahun (Source: Author's field survey data, 2015).

Table 1. Local residents' perception on gold mining visible environmental impacts (Source: Author's field survey data, 2015).

\begin{tabular}{|c|c|c|c|c|c|}
\hline $\begin{array}{l}\text { Which effect are visible on the } \\
\text { environment }\end{array}$ & $\begin{array}{l}\text { Frequency } \\
\text { (n) }\end{array}$ & $\begin{array}{c}\text { Percentage } \\
(\%)\end{array}$ & $\begin{array}{l}\text { Scale of } \\
\text { impacts }\end{array}$ & $\begin{array}{c}\text { Frequency } \\
\text { (n) }\end{array}$ & $\begin{array}{c}\text { Percentage } \\
(\%)\end{array}$ \\
\hline Turbidity and diversion of streams & 27 & 27.84 & Insignificant & 2 & 5.56 \\
\hline Soil depression & 36 & 37.11 & Significant & 28 & 77.78 \\
\hline Air pollution & 0 & 0 & Very & & \\
\hline Creation of pools of water & 34 & 35.05 & significant & 6 & 16.66 \\
\hline Total & $97^{*}$ & 100.00 & Total & 36 & 100.00 \\
\hline
\end{tabular}

${ }^{\star} \mathrm{NB}$ : Responses represent respondents' first choice (a lot of them noted more than one visible impact).

water borne diseases such as malaria account for $35.05 \%$, while turbidity and diversion of stream account for $27.84 \%$. None of the respondent noted air pollution as a visible effect of artisanal gold mining on the environment.

An accurate evaluation of environmental impacts is a capital-intensive process which involves the efforts of experts [2] [6] and [8]. However, answering the question of significance as spelt in the questionnaire, the techniques of personal observation in conjunction with existing credible scientific evidence was used to verify the information of respondents that the present magnitude of the impacts noted earlier is significant and which bears the highest percentage of $77.78 \%$, followed by $16.66 \%$ for very significant (Table 1 ).

\subsubsection{Temporary Diversions, Siltation and Sedimentation of Local Streams} Artisanal gold mining operations are inherently disruptive to the environment. The most obvious effect of mining observed and attested to by respondents were the temporary diversions, siltation and sedimentation of local streams. Water body's disturbance by surface mining is caused where overburden is moved for washing (Plate 4). 


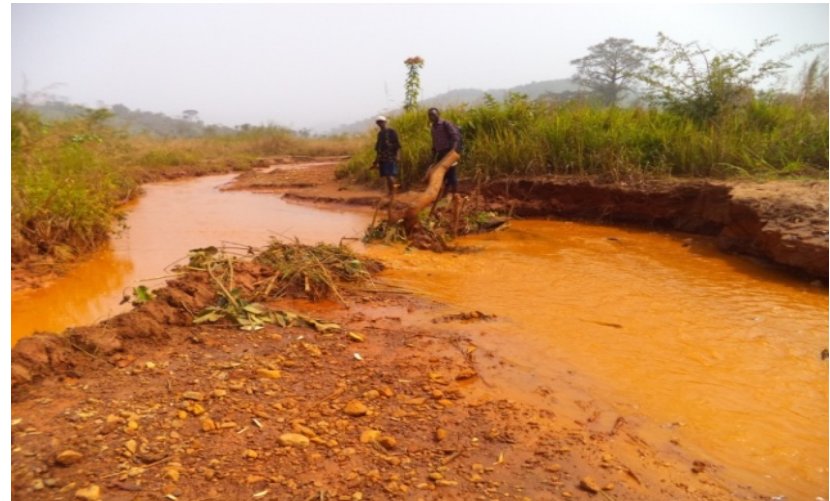

Plate 4. Evidence of stream turbidity, diversion, and sedimentation (Source: Author's field survey data, 2015).

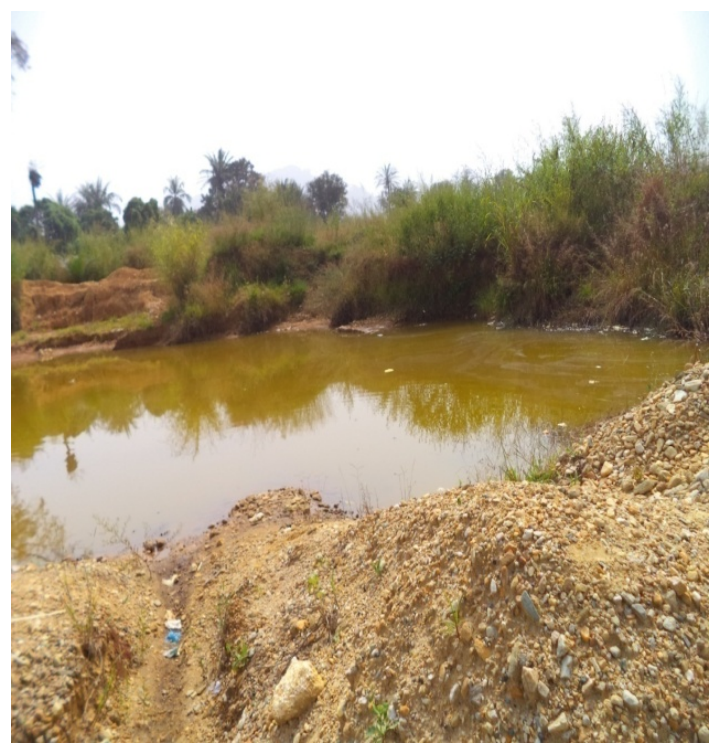

Plate 5. Evidence of visible environmental impacts. A scene of pool of water in an unfilled mined pit in Baomahun (Source: Author's field survey data, 2015).

\subsubsection{Creation of Water Pools}

The study revealed that after mining, miners left behind many unrecovered exploited mining pits. These pits cause animal traps and health hazard including serving as breeding grounds for vector of water borne diseases such as mosquitoes-the agent that spread malaria due to stagnant water collection after being abandoned by miners (Plate 5 ).

\subsubsection{Soil Depression}

The study has shown that artisanal gold mining is carried out in inland valley swamps that are used for rotational subsistence agriculture (i.e. rice cultivation and as well as vegetable gardening). The uncontrolled digging and turning over of top soil that is rich in plant nutrients by miners caused destruction of land beyond economic and technical reclamation and thus makes land unfit or unfavourable for agricultural use. Since agricultural productivity is closely linked to environmental factors including soil quality and water availability, provisioning ser- 
vices such as food (security) can be threatened or compromised by mining-related factors such as loss of agricultural land; water pollution; water supply. This may result to change in the surface hydrology (Plate 6).

\subsection{Effect of Artisanal Gold Mining on Environmental Health}

The health risks associated with mining in general related activities have out-weighed any social and economic or financial benefits that might accrue. Artisanal gold mining has a number of activities, each of which has potentially-adverse impacts on the health of communities based in close proximity to operations.

The study shows that residents suffered from mining related ailments. Malaria was recorded as the most prevalent and bears the highest percentage of $29.41 \%$; this is because the open mines left behind by mining carry stagnant water, which are favourable breeding grounds for mosquitoes. Cold and catarrh bears the second highest percentage of 17.65\%, followed by skin diseases (15.44\%) (Table 2).

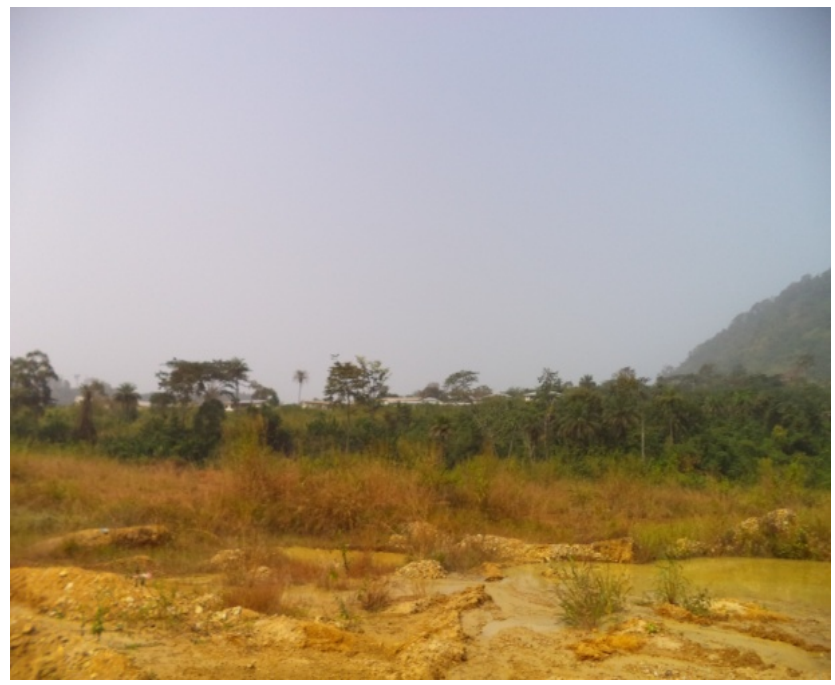

Plate 6. Scene of soil depression (Source: Author's field survey data, 2015).

Table 2. Diseases frequently contracted by respondents (Source: Author's field survey data, 2015).

\begin{tabular}{ccc}
\hline Health Diseases & Frequency & Percentage \\
\hline Malaria & 40 & 29.41 \\
Fever & 20 & 14.70 \\
Cold and Catarrh & 24 & 17.65 \\
Diarrhoea & 11 & 8.09 \\
Skin Diseases & 21 & 15.44 \\
Other (Dysentery, Stomach Ache) & 20 & 14.71 \\
Total & $136^{*}$ & 100.00
\end{tabular}

${ }^{*} \mathrm{NB}$ : responses represent respondents' first choice (there were a lot of them who noted more than one form of diseases). 


\subsection{Effect of Artisanal Gold Mining on Livelihood Foundation of Baomahun Local Communities}

The effects of artisanal gold mining on livelihood foundations of local people in Baomahun community presented a mixed picture of positive and negative impacts on a large spectrum of issues. Table 3 shows the data obtained from the local residents surveyed regarding the effects on livelihood experienced from artisanal gold mining in the community. Majority 23 (57.5\%) of respondents admit to have benefited considerably from gold mining in terms of improvement in their businesses, which they attribute to the presence of mining.

On the contrary, some of the other respondents who make up minority 17 (42.5\%) admitted that they have experienced the effects of the gold mining on their livelihood mainly as negative. The explanation they put forward was: Their livelihood is built on agriculture, and that Artisanal miners literally convert vast tracts of arable life-sustaining land (both rain-fed upland and swamp-based fields) into waste land. After mining for gold, gold miners leave behind a trail of destruction (the overburden and tailing) as evidenced by the deep unfilled pits. Topsoil buried and sub stratum is brought to the surface, this mix in soil strata make the soil unfit for agricultural purpose. Also the use of local streams for mineral concentration by artisanal miners results in accelerated evaporation of surface water posing a threat to water-use efficiency for agricultural activities of economic importance such as animal husbandry, aquaculture and irrigation. And agricultural productivity is closely linked to environmental factors including soil quality and water availability. Furthermore, few local residents said miners contaminate environmental goods and services, including provisioning services such as water and this have far reaching costs on entire families which have direct effect on households.

Haphazard deforestation due to the expansion of mining activities or the discovery of new mining "hot spots" can inadvertently have an adverse effect on the ability of the local non mining population with particular reference to forest users such as traditional healers who depend on the use of medicinal herbs from forest to achieve and sustain economic self-sufficiency.

\subsection{Implementation of Legal and Administrative Mining Policies}

Inadequate regulation and enforcement is a common observable fact in the artisanal mining sector. This is largely attributed to the political perceptions and

Table 3. Local residents' knowledge on gold mining impacts on livelihood (Source: Author's field survey data, 2015).

\begin{tabular}{ccc}
\hline $\begin{array}{c}\text { Does mining have any positive } \\
\text { impact on your livelihood }\end{array}$ & Frequency (n) & Percentage (\%) \\
Yes & 23 & 57.5 \\
No & 17 & 42.5 \\
Total & 40 & 100.00 \\
\hline
\end{tabular}


attitudes towards the sector as governments tend to favour the interests of and prioritized large concession holders whenever possible over artisanal mining. The research revealed that this political marginalization of the sector is undermining the policy and legal frameworks of the mining industries in myriad of ways, some of which are mention in the following list.

\subsubsection{The Use of Child Labour}

The study showed that in almost all mine sites visited, miners used children as labour to perform daily mining chores. This is in bridge of the national mining act and international law to which Sierra Leone is a signatory. This can increase the risk of exposure and addiction to alcohol and drugs. In addition, it can also disrupt or prevent their access to education (Plate 7).

\subsubsection{Assigned Number of Tributers per Acre}

The researcher had very good information on the numbers of tributers per artisanal mining license exceeded the set limits of fifty. This contravenes Section 91 sub section 3 of the Sierra Leone's Mines and Minerals Act of 2009. The ultimate drivers of this are the lack of trust and pursuance of individual interests by the stakeholders.

\subsubsection{Rehabilitation and Reclamation of Mined-Out Lands}

The study revealed that holders of artisanal mining license renew their licenses without undertaking rehabilitation and reclamation of mined out areas or paid the prescribed fee.

The Director and authorities responsible for the protection of the environment do not come inspect the mined out land prior to the renewal of a license as mandated by the act. This contradicts Section 90 sub sections 1 and 2; and Section 91 sub section 3 of the Sierra Leone's Mines and Minerals Act of 2009, respectively.

\section{Conclusions}

The research revealed that the methods used by artisanal gold miners in their

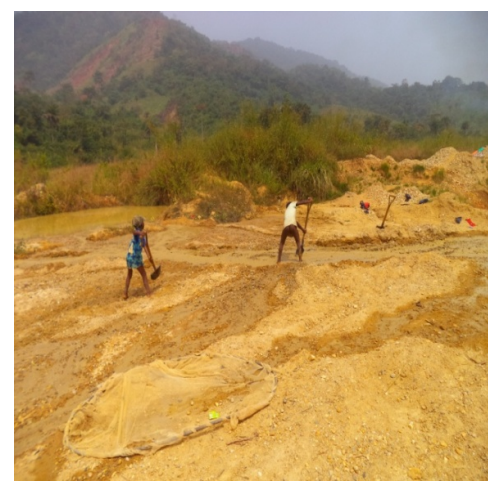

(a)

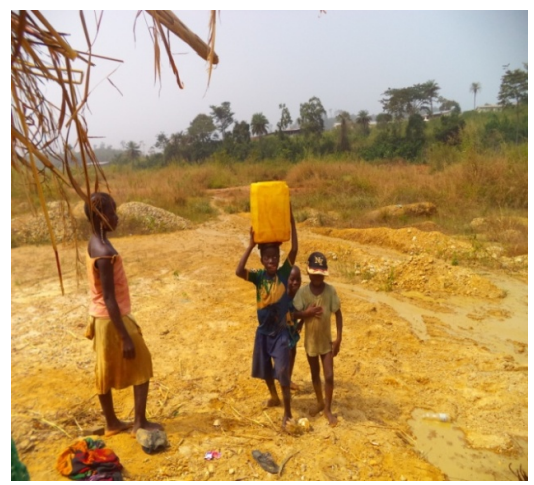

(b)

Plate 7. Undeniable evidence and proof of the use of child labour in mining site. (Source: Author's field survey data, 2015). 
operations vary and depend on: the geology and topography of the area; location, type, size and orientation of the mineral resource. In Baomahun, open pit mining method is used to dig and extract gold in inland valley swamps and forested areas, while both open pit mining and underground mining methods are used in the hills. The latter is practiced mainly in the dry season. The study has also shown that miners use chemicals such as elemental mercury as a supplementary technique to recover more gold particles from sediment.

Artisanal mining and large scale mining operations have some common effects on the environment but the nature and magnitude are different. The visible effects of artisanal gold mining on the environment are the soil depression and the creation of water pools in abandoned unfilled mines, temporary turbidity, diversions, and sedimentation of local streams.

Significant gaps and disparities exist in the implementation of the new Mines and Minerals act of 2009 on the artisanal mining sector. The research finds out that the number of tributers per artisanal mining license exceeds the set limits of fifty. There is undeniable evidence and proof of artisanal license renewal without the rehabilitation and reclamation of mined out areas by license holder. Evidence is rich on the use of child labour in artisanal mining site by miners.

\section{References}

[1] Samura, S. (2006) The Effect of Mining on Agricultural Production in SellaLimba Chiefdom, Bombali District, Northern Province of Sierra Leone. Master's Thesis, Njala University, Njala, 47 p.

[2] United Nations Environment Programme (2006) Africa Environment Outlook 2: Our Environment, Our Wealth. Volume 2 of Africa Environment Outlook. UNEP, Nairobi.

[3] Common Fund for Commodities (2008) Regional Workshop: Small-Scale Mining in Africa-A Case for Sustainable Livelihood. Department of Mineral Resources, Amsterdam.

[4] D’Souza, K. (2002) Artisanal and Small-Scale Mining in Africa: A Reality Check. Keynote Presentation at the Seminar on Artisanal and Small-Scale Mining in Africa, Yaoundé, Cameroon.

http://www.un.org/esa/sustdev/tech_coop/documents/seminar_Yaounde/Session1_ Souza.pdf

[5] Nkuli, G. (2008) Effects of Gold Mining Activities on the Water Quality of Bulyan-hulu River: The Case of Bulyanhulu Gold Mine in Shinyanga-Tanzania. Master's Thesis, University of Zimbabwe, Harare.

[6] United Nations Economic and Social Council, Economic Commission for Africa (2003) Reports on Selected Themes in Natural Resources Development in Africa: Artisanal and Small-Scale Mining and Technology Challenges in Africa. Third Meeting of the Committee on Sustainable Development, Addis Ababa, 7-10 October 2003, 21 p.

[7] Murwendo, T., Rusinga, O. and Zinhiva, H. (2011) The Role of Small-Scale Gold Mining in Promoting Sustainable Livelihoods among Local Communities in Kadoma District of Zimbabwe. Journal of Sustainable Development in Africa, 13, 191-200.

[8] Kitula, A.G.N. (2006) The Environmental and Socio-Economic Impacts of Mining on Local Livelihoods in Tanzania: A Case study of Geita District. Journal of Cleaner Production, 14, 405e414. 